\title{
Improvement of communication and interpersonal competence in telenursing - development of a self-assessment tool
}

Christina Johnson, Susan Wilhelmsson, Sussanne Börjeson and Malou Lindberg

\author{
Linköping University Post Print
}

Tweet

N.B.: When citing this work, cite the original article.

Original Publication:

Christina Johnson, Susan Wilhelmsson, Sussanne Börjeson and Malou Lindberg, Improvement of communication and interpersonal competence in telenursing - development of a selfassessment tool, 2015, Journal of Clinical Nursing, (24), 11-12, 1489-1501.

http://dx.doi.org/10.1111/jocn.12705

Copyright: Wiley: 12 months

http://eu.wiley.com/WileyCDA/

Postprint available at: Linköping University Electronic Press

http://urn.kb.se/resolve?urn=urn:nbn:se:liu:diva-119577 


\section{ABSTRACT}

Aims and objectives: The aim of this study was to develop a self-assessment tool aiming to raise telenurses' awareness of their communication and interpersonal competence, and highlight areas in need of improvement.

Background: Several studies have revealed the need for development of communication competence in telenursing. Structured analyses of conversations with patients/callers, is one way to increase telenurses' awareness of their unique communication and interpersonal competence.

Design: Instrument development, Validation assessment using the method Content Validity Index.

Method: The process to determine content validity was done in 2 stages; the development stage and the assessment stage. The development stage started with a literature search. The assessment stage was separated into 2 phases, assessment by an expert group and assessment and test by telenurses. The telenurses also participated in consensus discussions.

Results: A telenursing self-assessment tool with 58 items was developed. The items were sorted into 5 sections according to the nursing process.

Conclusion: This study describes the thorough development process of the Telenursing selfassessment tool to be used by telenurses in order to become aware of their unique communication and interpersonal competence when analysing their own conversations with patients/callers. As a formative tool it is meant to provide self-direction, feedback and coaching, and create learning opportunities

Relevance to clinical practice: The self-assessment tool helps the telenurse to follow the nursing process, to be patient-centred, and it is meant to provide self-direction, feedback, and coaching, as well as create learning opportunities. The tool can contribute to the development 
of communication and interpersonal competence in telephone advice nursing. Further development of the tool may provide an objective scoring instrument for evaluating communication training and education in the field.

Key words: telenursing, communication, nurse-patient relations, triage, clinical competence, hotlines, self-assessment, instrument development 


\section{What does this paper contribute to the wider global clinical community?}

- A self-assessment tool with 58 items, to be used by telenurses when analysing their own communication and interpersonal skills, has been developed.

- The self-assessment tool helps the telenurse to follow the nursing process, to be patientcentred, and it is meant to provide self-direction, feedback, and coaching, as well as create learning opportunities.

- In the future, the self-assessment tool could be developed and used as a scoring instrument by a neutral observer to evaluate communication training and education in the field. 


\section{Introduction}

In many Western countries, telephone advice nursing has expanded rapidly in the last decade, and are provided by telenurses in primary care, hospital clinics and large medical call centres. Researchers highlight telenurses' communication and interpersonal competence and the fact that the outcome of a telephone call depends on these competences (Nauright et al. 1999, Larson-Dahn 2001, Wahlberg \& Wredling 2001, Valanis et al. 2007). Since there is a lack of visual contact in telephone advice nursing, special communication competence is needed. Telenurses emphasize the importance of developing specific competences for relationship-building and communication in telephone-based encounters (Snooks et al. 2008). These competences are crucial for investigating and assessing symptoms (Wahlberg et al. 2005), reaching an agreement with the caller, working with the caller to develop a plan of action and for providing the information needed by the caller, in a way he/she understands (Larson-Dahn 2000, Moscato et al. 2007, Valanis et al. 2007).

The most common reasons for malpractice claims in telephone advice nursing have been identified as telenurses' failure to listen to the caller, communicate relevant issues concerning the health problem, and not asking the caller enough questions (Ernesäter et al. 2012). People in strategic positions with regard to patient safety work consider improvement of communication between health care professionals and patients as a very important area for improving patient safety in the future (Nygren et al. 2013). Valanis et al. (2003) have developed a model describing the factors that affect the outcomes of telephone advice nursing, where the interaction between the nurse and the caller is hypothesized to be the most important variable in the process of telenursing (Valanis et al. 2003). Valanis et al. (2007) also suggest that performance standards should be established, which can encourage effective communication behaviours, and that ways of measuring these behaviours should be developed and used regularly. Wahlberg et al. (2005) suggest that all telenurses should listen to 
recordings of their telephone calls on a regular basis in order to improve their communication skills. By using a standardized tool when analysing own audio-recordings, strengths and weaknesses in communication can be identified (Duffy et al. 2004). Due to this we have developed a self-assessment tool, meant to be used regularly by telenurses to analyse their own audio-recorded encounters with callers. The self-assessment tool aims to raise telenurses' awareness of their communication and interpersonal competence, and highlight areas in need of improvement.

Thus, the self-assessment tool assesses the concept communication and interpersonal competence adapted for the telenursing situation. Communication competence is defined in terms of specific tasks, such as effective questioning skills when interviewing patients. The concept interpersonal competence is described as process oriented, for example the establishment of a trusting relationship (Duffy et al. 2004).

In this study, the person who makes the phone call to the telephone advice nurse is referred to as "the caller", and the person with health problems is referred to as "the patient". The concepts "patient-centredness" and "patient satisfaction" include the caller as well.

\section{Background}

According to Swedish health care law, everyone in Sweden has the right to easy access to health care, including telephone contact. Therefore, telephone availability is followed and reported nationally on a regular basis (Swedish Association of Local Authorities and Regions 2013). In addition, the national telephone helpline, National Medical Advisory Service 1177 , operated by specially trained nurses, is open 24 hours a day. The nurses independently assess and triage health care needs, provide self-care advice and refer the caller to an appropriate level of health care (Ström et al. 2006). The service can be reached on 
telephone number 1177 (Swedish Association of Local Authorities and Regions 2005), and in 2013 it received approximately 5 million calls.

Several studies have revealed a need for the development of communication competence in telephone advice nursing (Moscato et al. 2007, Rahmqvist et al. 2011, Ernesäter et al. 2012). Structured analyses of conversations with callers is one way to increase telenurses' awareness of his/her unique communication and interpersonal competence. This requires a valid formative self-assessment tool (Duffy et al. 2004). A formative tool is used for teaching and could for example be a self-assessment guide or checklist of an individual's self-awareness of his/her learning needs. It provides self-direction, feedback and coaching, and creates learning opportunities (Banning 2004, Duffy et al. 2004). Wahlberg et al. (2005) suggest that listening regularly to own authentic calls should be compulsory for telephone nurses. When the present study was initiated we only found one instrument that focused on communication competence in telenursing. It was a rating scale developed in the Netherlands, aimed to be used by a peer colleague to assess the communication skills of call handlers in out-of-hours centres (Derkx et al. 2007). However, the instrument was not developed according to solid scientific principles (Lynn 1986, Polit \& Beck 2012), which is why we decided to develop a new self-assessment tool for telephone advice nursing based on earlier knowledge and relevant theories.

The telephone advisory call can be seen as a nursing process in 6 phases: assessment, nursing diagnosis, setting goals, planning, implementation and evaluation (table 1) (Rutenberg \& Greenberg 2012). The first phase, assessment, is based on the interview with the caller (Rutenberg 2000) and on symptomatic signs, such as wheezing or other background sounds (Wahlberg et al. 2005). The second phase, nursing diagnosis, is defined as urgency and the patient's needs. In the third phase, the goal or desired outcome of the encounter is set up and in the fourth step, a plan of action is developed in collaboration with the caller. In the fifth 
phase, implementation, the nurse gives the caller medical information and advice, information about self-care, directing the patient to the appropriate level of care or ordering an ambulance if necessary (Moscato et al. 2003, American Academy of Ambulatory Care Nursing 2012, Rutenberg \& Greenberg 2012). The implementation phase may also include health education (Nauright et al. 1999, Mayo et al. 2002, Wahlberg 2004), and support (Wahlberg et al. 2005). Larson-Dahn (2001) and Kaminsky et al. (2013) emphasize that health promotion must be included in telephone advice nursing, which complies with the Code of Ethics for Nurses (International Council of Nurses 2012), and Swedish healthcare legislation (The Ministry of Health and Social Affairs 1982). In the last phase of the nursing process, evaluation, the nurse makes sure that the caller understands the plan of action and that the nurse and caller agree on the plan. The caller's opinion and the outcome could also be investigated in other ways, for example by follow-up calls (Rutenberg 2000, Chang et al. 2002, American Academy of Ambulatory Care Nursing 2004, 2012). Good communication and interpersonal competence is crucial to be able to perform the phases mentioned above (Larson-Dahn 2000, Wahlberg et al. 2005, Valanis et al. 2007).

Table 1 The nursing process in telephone advice nursing

\begin{tabular}{|c|c|}
\hline Phase in nursing process & Examples of nursing actions \\
\hline \multirow[t]{4}{*}{ Assessment } & $\begin{array}{l}\text { Assessment of the patient's health problem, needs and purpose of the } \\
\text { call }\end{array}$ \\
\hline & Interviewing the caller \\
\hline & Listening to symptomatic signs, such as wheezing \\
\hline & Listening to other background sounds \\
\hline \multirow[t]{4}{*}{ Nursing diagnosis } & Determining actual or potential health problems \\
\hline & Prioritizing of urgency \\
\hline & Prioritizing of the patient's needs \\
\hline & Some of the NANDA diagnoses could also be applicable \\
\hline Setting goals & Decide the desired outcomes of the call \\
\hline
\end{tabular}




\begin{tabular}{ll}
\hline & $\begin{array}{l}\text { For instance, the caller will receive enough knowledge to be able to } \\
\text { perform self-care }\end{array}$ \\
& For instance, the caller will go to the emergency department \\
Is made in collaboration with the caller, for example how the patient \\
will get to the emergency department \\
Planning \\
Medical information \\
Self-care advice \\
Health education \\
Support \\
Health promotion \\
Mediation of contact with other health care settings \\
Ordering of an ambulance \\
Making sure that the nurse and caller agree on the plan of action \\
Checking that the caller understands the plan of action \\
Checking the caller's opinion \\
Checking the outcome by follow-up calls \\
\hline Evaluation
\end{tabular}

A patient-centred approach affects the communication and relationship with the patient and it has been shown to increase patient satisfaction along with other positive health outcomes such as better health status (Stewart et al. 2000). The concept of patient-centredness is however not clear (Holmström \& Röing 2010), but is often described as a bio-psychosocial view of the patient's health problem. It contains open-ended questions, discussions about how the illness impacts the patient, viewing the patient as an individual, shared power and responsibility, a strive for a common ground about the implementation, focus on the personal relationship between the professional and the patient, an awareness about the impact of the professionals' personality, and inclusion of health promotion and motivation in the conversation (Mead \& Bower 2000, Anderson 2002, Holmström \& Röing 2010). Studies have shown that even in telephone advice nursing, callers appreciate a patient-centred approach. Being engaged in the decision-making process, feeling that you are being listened to and that 
someone cares are important areas, as are reassurance and having confidence in the nurse and his/her judgment (Moscato et al. 2003, Ström et al. 2009).

The objective of this study was to develop a self-assessment tool aiming to raise telenurses' awareness of their communication and interpersonal competence, and highlight areas in need of improvement. 


\section{Methods and results}

\section{The tool development process}

This is a methodological and developmental study based on instrument development.

Content validity was assessed in 2 stages; the development stage and the assessment stage

(see Figure 1). The assessment stage was separated into 2 phases, assessment by an expert group, and assessment and test by telenurses. The telenurses also participated in consensus discussions.

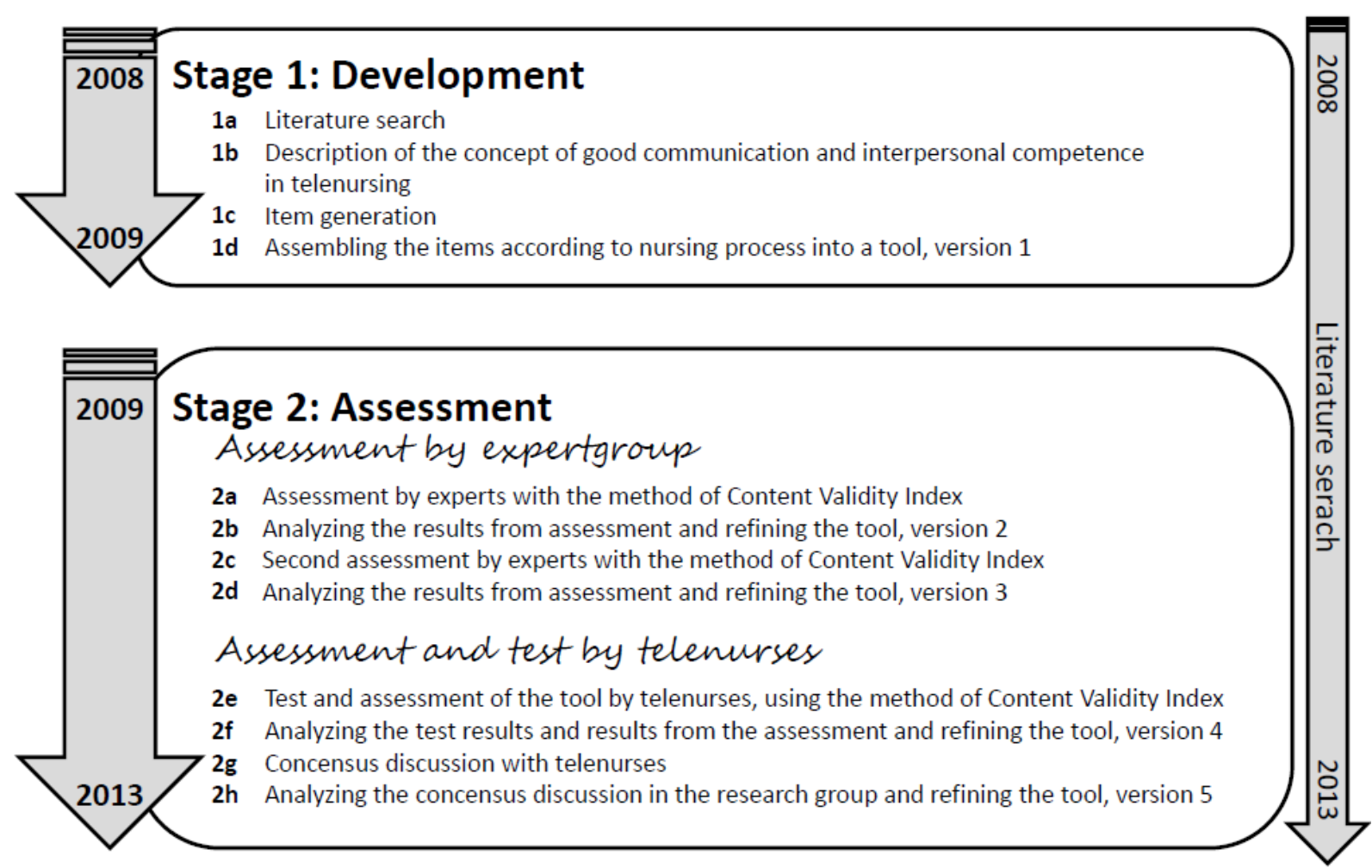

Figure 1.

\section{Development stage}

The development stage began with a literature search (step 1a, Figure 1) to identify communication and interpersonal skills in telenursing, focusing on patient satisfaction and 
patient safety (Lynn 1986, Polit \& Beck 2012). Since studies focusing on communication and interpersonal skills in telenursing are limited, physical meetings in primary care were also included in the literature search. Initially, 29 relevant papers were found. The literature search was thereafter continuously updated throughout the whole development and assessment process. The search terms used were communication, patient satisfaction, consumer satisfaction, nurse-patient relations, physician-patient relations, clinical competence, hotlines, telephone, remote consultation, remote counselling, interpersonal relations, telemedicine, patient safety, telephone advice nursing and triage. The concept "telenursing" was introduced as a Mesh term in 2009 and could not be used in the first search conducted in 2008. Based on the literature search, a summary describing the dimensions in communication and interpersonal competence in relation to telephone advice nursing interaction was prepared (step 1b, Figure 1). Next, an item pool was generated from the summary (step 1c, Figure 1). The items were arranged according to the phases in the nursing process, adapted to the telephone advice nursing call (Lynn 1986). The first version of the self-assessment tool (step 1d, Figure 1) consisted of 86 items.

\section{Assessment stage: the expert group}

The objective of the assessment stage was to evaluate content validity for each item in the tool and for the entire tool.

As a first step, a panel of 10 experts was asked to assess the items and the entire tool in a structured process (Lynn 1986). The experts were chosen to reflect a range of opinions and had varied experience in this area. Six were researchers with focus on communication in health care or telephone advice nursing, all with a nursing or general practitioner background. Three experts in the group were individuals with experience of calling the National Medical Advisory Service 1177 and one was an experienced telephone nurse. 
Each expert assessed the tool individually without any interaction with the other experts. They were given an information letter, a summary of the content area, the first version of the tool and instructions on how to assess each item in the tool. The experts were asked to consider whether each item was relevant and appropriate, and whether the items measured all dimensions of the content area. They rated each item on a 4-point scale: 1: an irrelevant item; 2: the item is relevant but in need of major adjustment; 3 : the item is relevant but in need of minor adjustment; 4: extremely relevant item. The experts were also asked to suggest improvements for the items with a score lower than 4 , and to assess if the content area was covered by the items and, if not, suggest new items (step 2a, Figure 1). These suggestions were analysed and discussed by the authors and changes were done when consensus was reached.

Based on the rating by the experts, a Content Validity Index (CVI) was computed for each item and for the full tool. The CVI for each item (I-CVI) was calculated as the proportion of experts who rated the item as 3 or 4 . The lowest accepted value of the I-CVI depends on the number of experts included in the assessment. With 10 experts, at least 8 had to rate an item as 3 or 4 to establish a CVI of 0.8 (Lynn 1986). Items with a lower value of ICVI would either have to be revised or removed (Lynn 1986, Polit \& Beck 2006). Ten of the items had a lower value than 0.8 after the first assessment and were all removed or revised. Due to comments from the experts, other items were also refined or pooled together. The CVI for the entire scale (S-CVI) was calculated as the average value of all the I-CVI values, called S-CVI/Ave (Polit \& Beck 2006). After the first assessment, S-CVI/Ave was 0.87. Our goal was to achieve an S-CVI/Ave value of 0.9 or higher (Lynn 1986, Waltz et al. 2005, Polit \& Beck 2006). Suggestions from the experts on missing areas were considered and 10 new items were added. The refinement process of the tool was done through discussion between the authors until consensus was reached. The second version of the tool consisted of 82 items 
(step 2b, Figure 1), and was sent to the same panel of experts for assessment, using an identical process, (step 2c, Figure 1). One of the experts could not be reached, so 9 questionnaires were returned. The required I-CVI value with 9 experts is 0.78 (Lynn 1986). Where there was an internal loss, the I-CVI was calculated for the number of available ratings. After the second assessment the S-CVI/Ave was 0.91, which is above requirement (Lynn 1986, Waltz et al. 2005, Polit \& Beck 2006). The I-CVI values for 5 items were below the required value. Analysis of the expert comments regarding these items was done as in the first revision. Some comments concerned the assignment of telephone advice nursing instead of the communication and interpersonal topic. The comments led to some revisions, but the number of items in the third version of the tool was still 82, (step 2d, Figure 1).

\section{Assessment stage: the telenurses}

A group of 10 telenurses were asked to test and assess the items and the entire tool in a structured process. Since the tool consisted of 82 items, a goal in this step was to reduce the number of items to make the tool more practical to use. The nurses were chosen to represent a variety of experiences, number of years in the profession, age and educational background. The nurses were all working at the National Medical Advisory Service 1177. All telephone calls to 1177 are automatically audio-recorded and must be saved and treated as other patient records. Every nurse has access to the recordings of his/her own patient encounters. According to Swedish legislation, recordings can be used for quality improvement, for example conversation analyses.

The nurses themselves selected calls to be analysed with the requirement that they should involve counselling regarding personal health problems. Each nurse tested the tool by analysing 4 audio-recorded encounters. One nurse analysed 3 encounters due to shortage of time. They were also asked to rate: a) the level of understanding for each item and b) the 
relevance of each item in order to develop their communication skills. The same method as described above (CVI) was used (step 2e, Figure 1). The S-CVI/Ave for relevance was 0.85 and 0.92 for the level of understanding.

Were there was an internal loss the I-CVI was calculated for the number of available ratings. There were 21 items with an I-CVI lower than accepted for relevance and 10 items with an I-CVI below the accepted value for level of understanding. The nurses' suggestions were analysed, which resulted in reformulation of some items and deletion of 26 items. One new item was added, and so the fourth version of the tool consisted of 57 items (step $2 \mathrm{f}$, Figure 1). This was done through discussion between the authors until consensus was reached.

The revised tool was sent to the same group of telenurses and important amendments were highlighted during 2 sessions of consensus discussions. Two nurses could not participate in the discussion groups, but submitted written comments instead (step 2g, Figure 1). The consensus discussion led to some reformulations and one new item was added (step $2 \mathrm{~h}$, Figure 1). The fifth version of the tool contained 58 items.

\section{The finalized Telenursing self-assessment tool}

The items in the final version of the self-assessment tool are sorted into 5 sections. The first section "Opening the call" ( 3 items), aims to evaluate if the nurse opens the call in a friendly and trustworthy manner. In the second section "Listening and assessing" (21 items), the items evaluate if the nurse listens actively, explores the caller's/patient's health problem, thoughts and fears about the health problem from various angles, and if the nurse makes sure that she/he has understood the caller properly etc. In the third section, "Defining diagnosis and goals, planning and intervention" (14 items), items evaluate if the nurse adapts information to the caller, has a health promotion approach, and makes the interventions in collaboration with the caller etc. In the 4th section, "Evaluation and conclusion" (6 items), the 
items evaluate if the nurse makes sure that the caller understands important information and whether the nurse checks if the caller has any further questions etc. There is also a 5th section, "Overall issues" (14 items), for items essential for the whole conversation and not just a specific section of the call (Table 2 and Appendix).

Every item is graded on a 4-point scale "Totally agree", "Mainly agree", "Agree to some extent" and "Disagree". Since the Telenursing self-assessment tool is meant to be useful for all types of nurse advice calls, there is a "N/A in this call" option for 23 of the items. The Telenursing self-assessment tool is meant to give telenurses feedback on their communication and interpersonal skills, and make the nurse aware of areas in need of improvement. As a next step, the tool will also be developed and tested as an objective scoring instrument.

Table 2 Examples of items from the Telenursing self-assessment tool

\begin{tabular}{|c|c|}
\hline Opening the call & $\begin{array}{l}\text { Introduces herself/himself clearly by name and title } \\
\text { Friendly tone of voice }\end{array}$ \\
\hline \multirow[t]{3}{*}{ Listening and assessing } & Expresses empathy, for instance through words, voice or intonation \\
\hline & Keen to the caller's feelings and confirms or names these \\
\hline & Talks about the caller's thoughts/fears/worries regarding the health problem \\
\hline \multirow{3}{*}{$\begin{array}{l}\text { Defining diagnosis and goals, planning and } \\
\text { intervention }\end{array}$} & Informs and explains according to the caller's needs and wishes \\
\hline & $\begin{array}{l}\text { Conducts a dialogue with the caller about plausible causes for the health } \\
\text { problem }\end{array}$ \\
\hline & $\begin{array}{l}\text { Establishes a plan of action together with the caller, which both feel will } \\
\text { work }\end{array}$ \\
\hline \multirow[t]{2}{*}{ Evaluation and conclusion } & Gives clear information about symptoms that the caller should look out for \\
\hline & $\begin{array}{l}\text { Gives clear information about what the caller should do if the symptoms } \\
\text { occur }\end{array}$ \\
\hline \multirow[t]{2}{*}{ Overall issues } & A friendly demeanour throughout the whole conversation \\
\hline & Avoids a paternalistic ${ }^{1}$ attitude \\
\hline
\end{tabular}

${ }^{1}$ Paternalism according to MacMillanDictionary.com: a system in which someone in authority advises and helps people but also controls them by not letting them make their own decisions and choices. 


\section{Ethical considerations}

This study was performed according to the Principles of the Declaration of Helsinki (World Medical Association 2013). All involved experts were given information about the study and that their participation was voluntary. Both panels of experts were guaranteed that all data would be treated confidentially. No information reported in this paper can be linked to any individual expert. Since this study is a theoretical development of a self-assessment tool without patient participation, ethical approval was not necessary according to Swedish legislation. In Sweden, every care unit is responsible for continuously working with quality improvements and follow up on activities. This study is a part of a quality improvement project and was authorized by the manager of the unit.

\section{Discussion}

In this study, we developed the Telenursing self-assessment tool aimed at improving communication and interpersonal competence among telenurses, as advocated by previous studies (Richards et al. 2004, Wahlberg et al. 2005, Valanis et al. 2007, Ström et al. 2011, Ernesäter et al. 2012). The present tool is the first scientifically developed formative tool that enables telenurses to regularly analyse their own calls in a defined work routine. The development of the Telenursing self-assessment tool and the determination of content validity was systematically performed (Lynn 1986, Polit \& Beck 2012) using evidence from the literature as well as 2 highly qualified expert groups. This study forms the basis for the development of an objective scoring instrument to evaluate communication training and education in the field.

The Telenursing self-assessment tool contains items on having a dialogue and developing a plan of action in collaboration with the caller. This is consistent with the 
findings of Ström et al. (2009). In their qualitative study describing callers' perceptions of receiving advice via a medical care helpline, the callers emphasized the importance of being involved in the decision-making process. A friendly and composed nurse who treated the caller with respect was also important, as was having their emotions confirmed (Strom et al. 2009), and these subjects are included as separate items in our tool. In a study by Kaminsky et al. (2013), parents who called on behalf of their children expressed a wish for the nurse to explore their worries and individualize the communication process. These subjects are covered by items in the Telenursing self-assessment tool. Röing et al. (2013) suggested that areas of particular importance for improving communication in telenursing is that the nurse listens actively, summarizes and verifies with the patient. This is also addressed by items in the tool.

An important asset of the present tool is that it includes items on health promotion, which conforms to the International Council of Nurses declaration that "Nurses have 4 fundamental responsibilities: to promote health, to prevent illness, to restore health and to alleviate suffering" (International Council of Nurses 2012, p. 1). In addition, health care legislation in Sweden states that health care shall work to prevent illness and promote health (Ministry of Health and Social Affairs 1982, National Board of Health and Welfare 2005). Telephone advice nursing cannot be excluded from that (Association for Telephone Counselling in Healthcare and Swedish Society of Nursing 2011), even though 2 of the experts in the panels did not fully agree that the nurse should discuss health promotion in the encounter with the caller. Kaminsky et al. (2009) have shown that there is variation in telephone advice nurses' understanding of their work. There is no strict consensus about what the service should offer. Hence, there is a need for clarification and discussion about the content of the service and the assignment of telephone advice nurses. The tool might contribute to a greater awareness of the topic. 
A strength of the method used in the study was that all important areas of communication and interpersonal competence were covered even when the number of items was reduced from 86 to 58 . The reduction in the number of items makes the tool more useful in practice, although some telenurses commented that the tool was too extensive; but as a formative tool, it should increase the individual's self-awareness of their learning needs and provide self-direction, feedback and coaching. The analysis also creates a learning opportunity, and no relevant areas should be omitted.

In the present study, there was debate in the consensus discussion on the telenurses responsibility for checking the caller's understanding of the plan of action. Ernesäter et al. (2012) analysed 41 calls involving malpractice claims in telenursing and found that the patient's understanding was only followed up in 6 cases. Researchers suggest that telenurses can check that the caller understands by asking the caller to repeat the advice given to ensure the patient safety (Hansen 2011, Ernesäter et al. 2012). Another important reason for discussing the understanding of recommendations is to improve the caller's satisfaction (Kaminsky et al. 2013). This was brought up in the consensus discussion in the present study and even though some telenurses argued that they cannot ask every caller to repeat the plan of action, the research group decided to formulate the item as "The caller summarizes the plan of action, either of their own accord or at the request of the nurse".

The Telenursing self-assessment tool has a patient-centred approach, which has been shown to benefit not just patient satisfaction but also health status (Stewart et al. 2000). In the Interaction Model of Client Health Behaviour (IMCHB), the interaction between the professional and the patient is also seen to be an important factor in influencing the patient's health decisions (Cox 1982). The model explains the patient's health decision as a result of the unique characteristics of each patient and the interaction with the health professional. The patient's characteristics determine their response to a health problem, which should be 
assessed by the nurse during the nursing process, so that the interaction can be tailored to fit the specific patient. The outcome is thus strongly affected by how well the health professional can individualize the interaction (Cox 1982, Cox 1984, Brown 1992). The present tool is consistent with the IMCHB, in which the interaction between the health professional and the caller is described in 4 components: affective support, health information, decisional control and professional competence (Cox 1982). These 4 components are represented in the tool.

The present study is based on a thorough literature search to ensure that all relevant qualitative and quantitative studies within the field were identified. Only a few studies described the relationship between communication and interpersonal competence and patient satisfaction in telephone advice nursing, therefore articles on encounters in primary health care were also included in the initial literature search; the conditions for the encounter could be compared with telephone advice nursing, for example when a patient seeks care for a new health problem.

In summary, the Telenursing self-assessment tool may contribute to a better interaction between telenurses and callers affecting not only patient safety and patient satisfaction but also the caller's health decisions and health status. It is also necessary for a neutral observer to assess telenurses communication and interpersonal competence, thus the Telenursing self-assessment tool will be developed further to become an objective scoring instrument.

\section{Conclusion and relevance to clinical practice}

This study describes the development process of the Telenursing self-assessment tool to be used by telenurses when analysing their own communication and interpersonal skills in order to become aware of their competence. As a formative tool, the Telenursing selfassessment tool is meant to provide self-direction, feedback and coaching, and create learning 
opportunities (Duffy et al. 2004) and it helps the telenurse to follow the nursing process and to be patient- centred. The Telenursing self-assessment tool can contribute to the development of communication and interpersonal competence in telephone advice nursing.

\section{Funding}

Grants were received from National Medical Advisory Service Ltd (in Swedish Sjukvardsradgivningen SVR AB) and from the County Council of Östergötland, Sweden.

\section{Conflict of interest}

No conflict of interest has been declared by the authors. 


\section{References}

American Academy of Ambulatory Care Nursing (2004) Telehealth Nursing Practice Administration and Practice Standards, N.p.

American Academy of Ambulatory Care Nursing (2012) Telehealth Nursing Practice SIG. Available at: http://www.aaacn.org/community/telehealth-nursing-practice-sig (accessed 26 November 2013).

Anderson EB (2002) Patient-centredness: a new approach. Nephrology News and Issues 16, 80-82.

Banning M (2004) The use of structured assessments, practical skills and performance indicators to assess the ability of pre-registration nursing students' to apply the principles of pharmacology and therapeutics to the medication management needs of patients. Nurse Education in Practice 4, 100-106.

Brown SJ (1992) Tailoring nursing care to the individual client: empirical challenge of a theoretical concept. Research in Nursing and Health 15, 39-46.

Chang B, Mayo A, Omery A (2002) Evaluating quality of telehealth advice nursing. Western Journal of Nursing Research 24, 583-590.

Cox C (1982) An interaction model of client health behaviour: theoretical prescription for nursing. Advances in nursing science 5, 41-56.

Cox C (1984) Empirical test of the interaction model of client health behavior. Research in Nursing and Health 7, 275-285.

Derkx HP, Rethans JJ, Knottnerus JA, Ram PM (2007) Assessing communication skills of clinical call handlers working at an out-of-hours centre:development of the RICE rating scale. British Journal of General Practice 57, 383-387. 
Duffy FD, Gordon GH, Whelan G, Cole-Kelly K, Frankel R, Buffone N, Lofton S, Wallace M, Goode L, Langdon L, Participants in the American Academy on Physician and Patient's Conference on Education and Evaluation of Competence in Communication and Interpersonal Skills (2004) Assessing competence in communication and interpersonal skills: the Kalamazoo II report. Academic Medicine 79, 495-507.

Ernesäter A, Winblad U, Engström M, Holmström IK (2012) Malpractice claims regarding calls to Swedish telephone advice nursing: what went wrong and why? Journal of Telemedicin and Telecare 18, 379-383.

Hansen Holm E, Hunskaar S (2011) Understanding of and adherence to advice after telephone counselling by nurse: a survey among callers to a primary emergency out-of-hours service in Norway. Scandinavian Journal of Trauma, Resuscitation and Emergency Medicine 19, 48.

Holmström I, Röing M (2010) The relation between patient-centredness and patient empowerment: a discussion on concepts. Patient education and counselling 79, 167172.

International council of nurses (2012) The ICN code of ethics for nurses. Available at: http://www.icn.ch/images/stories/documents/about/icncode_english.pdf (accessed 26 November 2013).

Kaminsky E, Rosenqvist U, Holmström I (2009) Telenurses' understanding of work: detective or educator? Journal of Advanced Nursing 65, 382-390.

Kaminsky E (2013) Telephone nursing, stakeholder views and understandings from a paediatric and a gender perspective. Doctoral dissertation, Department of public health and caring sciences Uppsala University, Uppsala, Sweden. 
Larson-Dahn ML (2000) Tel-eNurse Practice: a practice model for role expansion. Journal of Nursing Administration 30, 519-523.

Larson-Dahn ML (2001) Tel-eNurse Practice. Quality of care and patient outcomes. The Journal of Nursing Administration 31, 145-152.

Lynn MR (1986) Determination and quantification of content validity. Nursing Research 35, $382-385$.

Mayo AM, Chang BL, Omery A (2002) Use of protocols and guidelines by telephone nurses. Clinical Nursing Research 11, 204-219.

Mead N, Bower P (2000) Patient-centredness: a conceptual framework and review of the empirical literature. Social Science \& Medicine 51, 1087-1110.

Moscato SR, David M, Valanis B, Gullion CM, Tanner C, Shapiro S, Izumi S, Mayo A (2003) Tool development for measuring caller satisfaction and outcome with telephone advice nursing. Clinical Nursing Research 12, 266-281.

Moscato SR, Valanis B, Gullion CM, Tanner C, Shapiro SE, Izumi S (2007) Predictors of patient satisfaction with telephone nursing services. Clinical Nursing Research 16, 119-137.

National Board of Health and Welfare (2005) Competence Description for Registered Nurses (in Swedish). Available at:

http://www.socialstyrelsen.se/lists/artikelkatalog/attachments/9879/2005-105-

1_20051052.pdf (accessed 26 November 2013).

Nauright LP, Moneyham L, Williamson J (1999) Telephone triage and consultation: an emerging role for nurses. Nursing Outlook 47, 219-226. 
Nygren M, Roback K, Öhrn A, Rutberg H, Rahmqvist M, Nilsen P (2013) Factors influencing patient safety in Sweden: perceptions of patient safety officers in the county councils. BMC Health Service Research 13, 52.

Polit DF, Beck CT (2012) Nursing Research: Principles and Methods. Lippincott Williams \& Wilkins, Philadelphia, PA.

Polit DF, Beck CT (2006) The content validity index: are you sure you know what's being reported? Critique and recommendations. Research in Nursing \& Health 29, 489-497.

Rahmqvist M, Ernesäter A, Holmström I (2011) Triage and patient satisfaction among callers in Swedish computer-supported telephone advice nursing. Journal of Telemedicine and Telecare 17, 397-402.

Richards D, Meakins J, Tawfik J, Godfrey L, Dutton E, Heywood P (2004) Quality monitoring of nurse telephone triage: pilot study. Journal of Advanced Nursing 47, $551-560$.

Rutenberg C (2000) Telephone triage. American Journal of Nursing 100, 77-81.

Rutenberg C, Greenberg L (2012) The Art and Science of Telephone Triage: How to Practice Nursing Over the Phone. Janetti Publications, Pitman, NJ.

Röing M, Rosenqvist U, Holmström IK (2013) Threats to patient safety in telenursing as revealed in Swedish telenurses' reflections on their dialogues. Scandinavian Journal of Caring Science 27, 969-976.

Snooks H, Williams A, Griffiths L, Peconi J, Rance J, Snelgrove S, Sarangi S, Wainwright P, Cheung WY (2008) Real nursing? The development of telenursing. Journal of Advanced Nursing 61, 631-640. 
Stewart M, Brown JB, Donner A, McWhinney IR, Oates J, Weston WW, Jordan J (2000) The impact of patient-centred care on outcomes. The Journal of Family Practice 49, 796804.

Ström M, Marklund B, Hildingh C (2006) Nurses’ perceptions of providing advice via a telephone care line. British Journal of Nursing 15, 1119-1125.

Ström M, Marklund B, Hildingh C (2009) Callers' perceptions of receiving advice via a medical care help line. Scandinavian Journal of Caring Sciences 23, 682-690.

Ström M, Baigi A, Hildingh C, Mattsson B, Marklund B (2011) Patient care encounters with the MCHL: a questionnaire study. Scandinavian Journal of Caring Sciences 25, 517524.

The Association for Telephone Counselling in Healthcare and Swedish Society of Nursing (2011) Competence description for telenurses (in Swedish). Available at: http://www.esh.se/fileadmin/erstaskondal/Alumni/vanforeningen/vanforeningen_komp etensbeskrivning telefonsjukskoterska.pdf (accessed 21 January 2014).

The Ministry of Health and Social Affairs (1982) Swedish Health Care Act (1982:763). Available at: http://www.notisum.se/rnp/sls/lag/19820763.HTM (accessed 26 November 2013).

The Swedish Association of Local Authorities and Regions (2005) Ring 1177 till sjukvårdsrådgivningen- från vision till verklighet (in Swedish). N.p.

The Swedish Association of Local Authorities and Regions (2013) Waiting times in health care (in Swedish). Available at: http://www.vantetider.se/ (accessed 26 November 2013). 
Valanis B, Tanner C, Moscato SR, Shapiro S, Izumi S, David M, Keyes C, Mayo A (2003) A model for examining predictors of outcomes of telephone nursing advice. Journal of Nursing Administration 33, 91-95.

Valanis BG, Gullion CM, Moscato SR, Tanner C, Izumi S, Shapiro SE (2007) Predicting Patient Follow-Through on Telephone Nursing Advice. Clinical Nursing Research 16, 251-269.

Wahlberg AC, Wredling R (2001) Telephone advice nursing-callers' experiences. Journal of Telemedicine and Telecare 7, 272-276.

Wahlberg AC (2004) Telephone advice nursing, callers' perceptions, nurses' experience of problems and basis for assessments. Doctoral dissertation, Department of Nursing, Karolinska Institutet, Stockholm, Sweden.

Wahlberg AC, Cedersund E, Wredling R (2005) Bases for assessments made by telephone advice nurses. Journal of Telemedicin and Telecare 11, 403-407.

Waltz CF, Strickland OL, Lenz ER (2005) Measurement in Nursing and Health Research. Springer, New York.

World Medical Association (2013) Declaration of Helsinki- Ethical principles for medical research involving human subjects. Available at:

http://www.wma.net/en/30publications/10policies/b3/index.html (accessed 27

February 2014). 


\section{Telenursing self-assessment tool}

2014 Christina Johnson

\section{Opening the call}

The goal of this phase is to establish contact and create an atmosphere where the caller feels invited to talk about their health problem.

\begin{tabular}{|c|c|c|c|c|c|c|}
\hline & & Disagree & $\begin{array}{l}\text { Agree to } \\
\text { some } \\
\text { extent }\end{array}$ & $\begin{array}{l}\text { Mainly } \\
\text { agree }\end{array}$ & $\begin{array}{l}\text { Totally } \\
\text { agree }\end{array}$ & $\begin{array}{l}\text { N/A in } \\
\text { this call }\end{array}$ \\
\hline 1. & $\begin{array}{l}\text { Introduces } \\
\text { herself/himself } \\
\text { clearly by name and } \\
\text { title }\end{array}$ & $\square$ & $\square$ & $\square$ & $\square$ & \\
\hline 2. & $\begin{array}{l}\text { Friendly tone of } \\
\text { voice }\end{array}$ & $\square$ & $\square$ & $\square$ & $\square$ & \\
\hline 3. & $\begin{array}{l}\text { Encourages and } \\
\text { invites the caller to } \\
\text { talk }\end{array}$ & $\square$ & $\square$ & $\square$ & $\square$ & $\square$ \\
\hline
\end{tabular}

\section{Listening and assessing}

The goal of this phase is to listen actively and explore the caller's health problem and, if relevant, its influence on the caller's life. The goal is also to explore the caller's thoughts and fears concerning the health problem. The caller's wish with the call should be identified, and the nurse and the caller should attain a concordant view of the health problem. In this phase, the nurse should acquire all the information required in order to define diagnosis and goals.

\begin{tabular}{|l|l|l|l|l|l|l|}
\hline & Disagree & $\begin{array}{l}\text { Agree to } \\
\text { some extent }\end{array}$ & $\begin{array}{l}\text { Mainly } \\
\text { agree }\end{array}$ & $\begin{array}{l}\text { Totally } \\
\text { agree }\end{array}$ & $\begin{array}{l}\text { N/A in } \\
\text { this call }\end{array}$ \\
\hline 4. & $\begin{array}{l}\text { Allows the caller to } \\
\text { speak without } \\
\text { being interrupted }\end{array}$ & $\square$ & & & & \\
\hline $\mathbf{5 .}$ & $\begin{array}{l}\text { Asks to speak } \\
\text { directly to the } \\
\text { patient }\end{array}$ & $\square$ & $\square$ & $\square$ & & \\
\hline
\end{tabular}




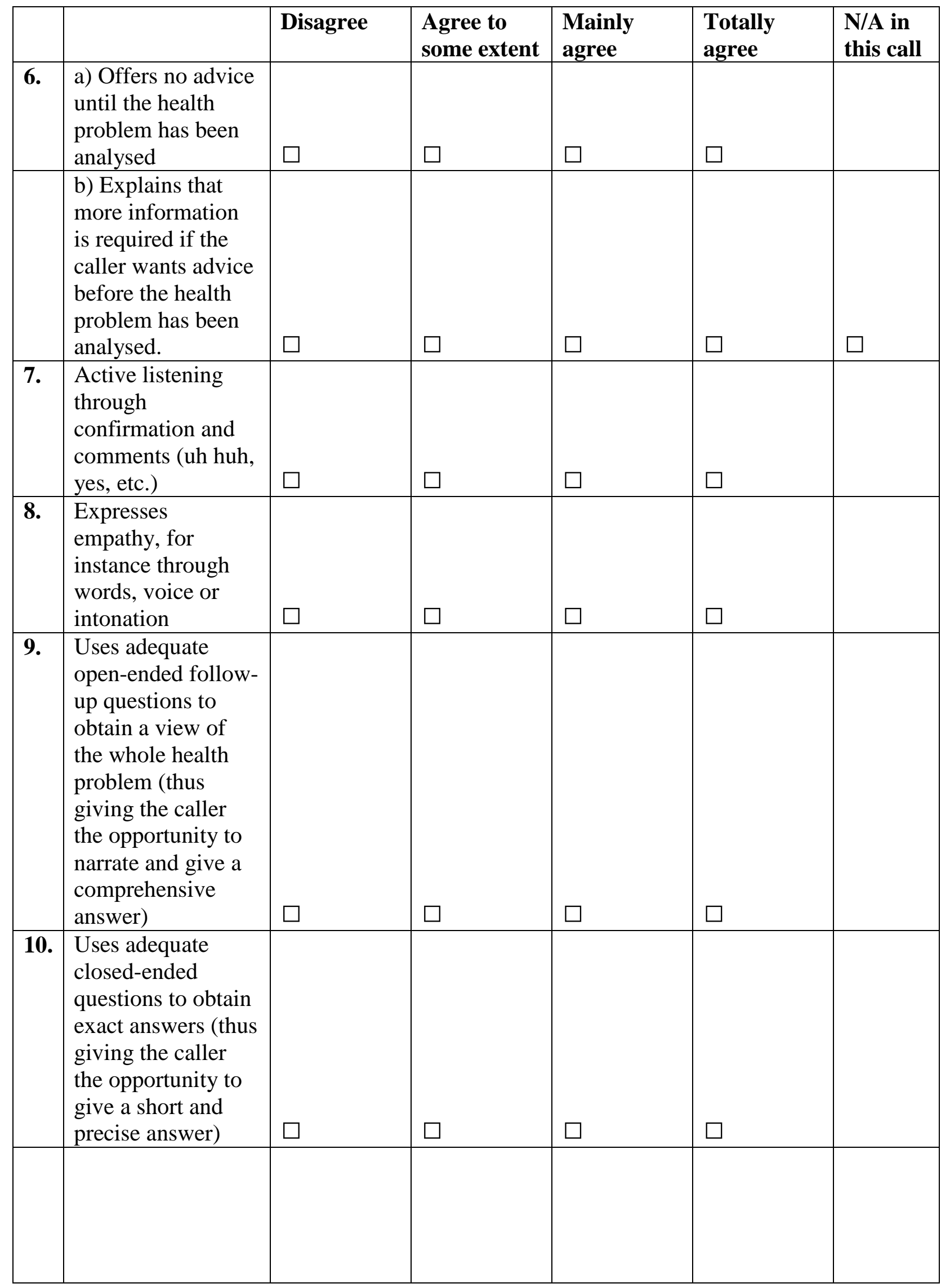


Telenursing self-assessment tool

2014 Christina Johnson

\begin{tabular}{|c|c|c|c|c|c|c|}
\hline & & Disagree & $\begin{array}{l}\text { Agree to } \\
\text { some extent }\end{array}$ & $\begin{array}{l}\text { Mainly } \\
\text { agree }\end{array}$ & $\begin{array}{l}\text { Totally } \\
\text { agree }\end{array}$ & $\begin{array}{l}\text { N/A in } \\
\text { this call }\end{array}$ \\
\hline 11. & $\begin{array}{l}\text { Keen to the caller's } \\
\text { feelings and } \\
\text { confirms or names } \\
\text { these }\end{array}$ & $\square$ & $\square$ & $\square$ & $\square$ & $\square$ \\
\hline 12. & $\begin{array}{l}\text { Elucidates what } \\
\text { has been said } \\
\text { through } \\
\text { paraphrases }\end{array}$ & $\square$ & $\square$ & $\square$ & $\square$ & $\square$ \\
\hline 13. & $\begin{array}{l}\text { Gives the caller an } \\
\text { opportunity to } \\
\text { correct elucidations }\end{array}$ & $\square$ & $\square$ & $\square$ & $\square$ & $\square$ \\
\hline 14. & Talks about: & & & & & \\
\hline & $\begin{array}{l}\text { a) the caller's } \\
\text { thoughts/fears/ } \\
\text { worries regarding } \\
\text { the health problem }\end{array}$ & $\square$ & $\square$ & $\square$ & $\square$ & \\
\hline & $\begin{array}{l}\text { b) how the health } \\
\text { problem influences } \\
\text { the caller's daily } \\
\text { life }\end{array}$ & $\square$ & $\square$ & $\square$ & $\square$ & $\square$ \\
\hline & $\begin{array}{l}\text { c) the caller's } \\
\text { wishes/ } \\
\text { expectations in } \\
\text { connection with the } \\
\text { call }\end{array}$ & $\square$ & $\square$ & $\square$ & $\square$ & \\
\hline 15. & $\begin{array}{l}\text { Observes non- } \\
\text { verbal sounds such } \\
\text { as coughing/ } \\
\text { indications of pain } \\
\text { or background } \\
\text { noise that are } \\
\text { relevant to the } \\
\text { health problem. }\end{array}$ & $\square$ & $\square$ & $\square$ & $\square$ & $\square$ \\
\hline
\end{tabular}


Telenursing self-assessment tool

2014 Christina Johnson

\begin{tabular}{|c|c|c|c|c|c|c|}
\hline & & Disagree & $\begin{array}{l}\text { Agree to } \\
\text { some extent }\end{array}$ & $\begin{array}{l}\text { Mainly } \\
\text { agree }\end{array}$ & $\begin{array}{l}\text { Totally } \\
\text { agree }\end{array}$ & $\begin{array}{l}\text { N/A in } \\
\text { this call }\end{array}$ \\
\hline \multirow[t]{5}{*}{16.} & Summarises: & & & & & \\
\hline & $\begin{array}{l}\text { a) the caller's } \\
\text { health problem }\end{array}$ & $\square$ & $\square$ & $\square$ & $\square$ & \\
\hline & $\begin{array}{l}\text { b) how the health } \\
\text { problem influences } \\
\text { the caller's daily } \\
\text { life }\end{array}$ & $\square$ & $\square$ & $\square$ & $\square$ & $\square$ \\
\hline & $\begin{array}{l}\text { c) the caller's } \\
\text { thoughts/fears/ } \\
\text { worries regarding } \\
\text { the health problem }\end{array}$ & $\square$ & $\square$ & $\square$ & $\square$ & $\square$ \\
\hline & $\begin{array}{l}\text { d) the caller's } \\
\text { wishes/ } \\
\text { expectations in } \\
\text { connection with the } \\
\text { call }\end{array}$ & $\square$ & $\square$ & $\square$ & $\square$ & \\
\hline 17. & $\begin{array}{l}\text { Gives the caller an } \\
\text { opportunity to } \\
\text { confirm whether } \\
\text { the summary is } \\
\text { correct }\end{array}$ & $\square$ & $\square$ & $\square$ & $\square$ & \\
\hline 18. & $\begin{array}{l}\text { Asks the caller } \\
\text { what they } \\
\text { themselves } \\
\text { know/have } \\
\text { read/have found } \\
\text { out about the } \\
\text { health problem }\end{array}$ & $\square$ & $\square$ & $\square$ & $\square$ & $\square$ \\
\hline
\end{tabular}


Defining diagnosis and goals, planning and intervention

The goal of these phases is that the nurse should define the diagnosis and goals and in collaboration with the caller find a feasible solution to the caller's health problem, and strengthen their ability to solve similar health problems on their own in the future.

\begin{tabular}{|c|c|c|c|c|c|c|}
\hline & & Disagree & $\begin{array}{l}\text { Agree to } \\
\text { some extent }\end{array}$ & $\begin{array}{l}\text { Mainly } \\
\text { agree }\end{array}$ & $\begin{array}{l}\text { Totally } \\
\text { agree }\end{array}$ & $\begin{array}{l}\text { N/A in } \\
\text { this call }\end{array}$ \\
\hline 19. & $\begin{array}{l}\text { If possible, gives a } \\
\text { plausible medical } \\
\text { explanation to the } \\
\text { health problem so } \\
\text { that the caller will } \\
\text { understand the } \\
\text { background of the } \\
\text { assessment and } \\
\text { advice }\end{array}$ & $\square$ & $\square$ & $\square$ & $\square$ & $\square$ \\
\hline 20. & $\begin{array}{l}\text { Informs and } \\
\text { explains according } \\
\text { to the caller's } \\
\text { needs and wishes }\end{array}$ & $\square$ & $\square$ & $\square$ & $\square$ & \\
\hline 21. & $\begin{array}{l}\text { Seeks confirmation } \\
\text { that information } \\
\text { about the health } \\
\text { condition can be } \\
\text { given although the } \\
\text { caller has not asked } \\
\text { for it }\end{array}$ & $\square$ & $\square$ & $\square$ & $\square$ & $\square$ \\
\hline 22. & $\begin{array}{l}\text { Conducts a } \\
\text { dialogue with the } \\
\text { caller about } \\
\text { plausible causes for } \\
\text { the health problem }\end{array}$ & $\square$ & $\square$ & $\square$ & $\square$ & $\square$ \\
\hline 23. & $\begin{array}{l}\text { Encourages the } \\
\text { caller to ask } \\
\text { questions }\end{array}$ & $\square$ & $\square$ & $\square$ & $\square$ & \\
\hline 24. & $\begin{array}{l}\text { Takes time to } \\
\text { answer questions } \\
\text { and explain }\end{array}$ & $\square$ & $\square$ & $\square$ & $\square$ & \\
\hline
\end{tabular}


Telenursing self-assessment tool

2014 Christina Johnson

\begin{tabular}{|c|c|c|c|c|c|c|}
\hline & & Disagree & $\begin{array}{l}\text { Agree to } \\
\text { some extent }\end{array}$ & $\begin{array}{l}\text { Mainly } \\
\text { agree }\end{array}$ & $\begin{array}{l}\text { Totally } \\
\text { agree }\end{array}$ & $\begin{array}{l}\text { N/A in } \\
\text { this call }\end{array}$ \\
\hline 25. & $\begin{array}{l}\text { Talks about what } \\
\text { actions the caller } \\
\text { has carried out to } \\
\text { deal with the health } \\
\text { problem }\end{array}$ & $\square$ & $\square$ & $\square$ & $\square$ & $\square$ \\
\hline 26. & $\begin{array}{l}\text { Encourages and } \\
\text { confirms the } \\
\text { caller's own } \\
\text { initiative to self- } \\
\text { care }\end{array}$ & $\square$ & $\square$ & $\square$ & $\square$ & $\square$ \\
\hline 27. & $\begin{array}{l}\text { Provides clear } \\
\text { information about } \\
\text { self-care }\end{array}$ & $\square$ & $\square$ & $\square$ & $\square$ & $\square$ \\
\hline 28. & $\begin{array}{l}\text { Does not use } \\
\text { evaluative words } \\
\text { and does not } \\
\text { lecture }\end{array}$ & $\square$ & $\square$ & $\square$ & $\square$ & \\
\hline 29. & $\begin{array}{l}\text { Talks about health } \\
\text { promotion and } \\
\text { preventive actions }\end{array}$ & $\square$ & $\square$ & $\square$ & $\square$ & $\square$ \\
\hline 30. & $\begin{array}{l}\text { Motivates } \\
\text { suggested actions } \\
\text { (including } \\
\text { advantages and } \\
\text { possible } \\
\text { disadvantages) }\end{array}$ & $\square$ & $\square$ & $\square$ & $\square$ & \\
\hline 31. & $\begin{array}{l}\text { Establishes a plan } \\
\text { of action together } \\
\text { with the caller, } \\
\text { which both feel } \\
\text { will work }\end{array}$ & $\square$ & $\square$ & $\square$ & $\square$ & \\
\hline 32. & $\begin{array}{l}\text { Considers } \\
\text { alternatives if the } \\
\text { caller is unhappy } \\
\text { with the plan of } \\
\text { action }\end{array}$ & $\square$ & $\square$ & $\square$ & $\square$ & $\square$ \\
\hline
\end{tabular}


Telenursing self-assessment tool

2014 Christina Johnson

\section{Evaluation and conclusion}

The goal of this phase is to check that the caller and the nurse agree on what the caller should do next, if the caller has understood important information, and if he/she is happy and feels that their questions have been answered.

\begin{tabular}{|c|c|c|c|c|c|c|}
\hline & & Disagree & $\begin{array}{l}\text { Agree to } \\
\text { some extent }\end{array}$ & $\begin{array}{l}\text { Mainly } \\
\text { agree }\end{array}$ & $\begin{array}{l}\text { Totally } \\
\text { agree }\end{array}$ & $\begin{array}{l}\text { N/A in } \\
\text { this call }\end{array}$ \\
\hline \multirow[t]{2}{*}{33.} & $\begin{array}{l}\text { a) Gives clear } \\
\text { information about } \\
\text { symptoms that the } \\
\text { caller should look } \\
\text { out for }\end{array}$ & $\square$ & $\square$ & $\square$ & $\square$ & \\
\hline & $\begin{array}{l}\text { b) Gives clear } \\
\text { information about } \\
\text { what the caller } \\
\text { should do if the } \\
\text { symptoms occur }\end{array}$ & $\square$ & $\square$ & $\square$ & $\square$ & \\
\hline 34. & $\begin{array}{l}\text { Summarises the } \\
\text { plan of action } \\
\text { which they have } \\
\text { both agreed upon }\end{array}$ & $\square$ & $\square$ & $\square$ & $\square$ & \\
\hline 35. & $\begin{array}{l}\text { The caller } \\
\text { summarises the } \\
\text { plan of action, } \\
\text { either of their own } \\
\text { accord or on } \\
\text { request }\end{array}$ & $\square$ & $\square$ & $\square$ & $\square$ & $\square$ \\
\hline 36. & $\begin{array}{l}\text { Checks that the } \\
\text { caller's questions } \\
\text { have been } \\
\text { answered, unless } \\
\text { evident }\end{array}$ & $\square$ & $\square$ & $\square$ & $\square$ & \\
\hline 37. & $\begin{array}{l}\text { Checks that the } \\
\text { caller is happy with } \\
\text { the call, unless } \\
\text { evident }\end{array}$ & $\square$ & $\square$ & $\square$ & $\square$ & \\
\hline
\end{tabular}


Telenursing self-assessment tool

2014 Christina Johnson

\section{Overall issues}

\begin{tabular}{|c|c|c|c|c|c|c|}
\hline & & Disagree & $\begin{array}{l}\text { Agree to } \\
\text { some extent }\end{array}$ & $\begin{array}{l}\text { Mainly } \\
\text { agree }\end{array}$ & $\begin{array}{l}\text { Totally } \\
\text { agree }\end{array}$ & $\begin{array}{l}\text { N/A in } \\
\text { this call }\end{array}$ \\
\hline 38. & $\begin{array}{l}\text { Expresses } \\
\text { themselves plainly } \\
\text { and clearly }\end{array}$ & $\square$ & $\square$ & $\square$ & $\square$ & \\
\hline 39. & \begin{tabular}{|l|} 
Shows \\
determination
\end{tabular} & $\square$ & $\square$ & $\square$ & $\square$ & \\
\hline 40. & $\begin{array}{l}\text { Mediates relevant } \\
\text { expert knowledge }\end{array}$ & $\square$ & $\square$ & $\square$ & $\square$ & \\
\hline 41. & $\begin{array}{l}\text { Refers to relevant } \\
\text { sources of } \\
\text { information }\end{array}$ & $\square$ & $\square$ & $\square$ & $\square$ & $\square$ \\
\hline 42. & $\begin{array}{l}\text { A friendly } \\
\text { demeanour } \\
\text { throughout the call }\end{array}$ & $\square$ & $\square$ & $\square$ & $\square$ & \\
\hline 43. & $\begin{array}{l}\text { Shows respect for } \\
\text { the caller }\end{array}$ & $\square$ & $\square$ & $\square$ & $\square$ & \\
\hline 44. & Shows empathy & $\square$ & $\square$ & $\square$ & $\square$ & \\
\hline 45. & \begin{tabular}{|l|} 
Does not use \\
judgemental/ \\
evalutative words \\
or intonation
\end{tabular} & $\square$ & $\square$ & $\square$ & $\square$ & \\
\hline 46. & $\begin{array}{l}\text { Politely returns the } \\
\text { conversation to the } \\
\text { health problem if } \\
\text { the caller digresses } \\
\text { from the subject or } \\
\text { talks for an } \\
\text { unreasonably long } \\
\text { time }\end{array}$ & $\square$ & $\square$ & $\square$ & $\square$ & $\square$ \\
\hline 47. & $\begin{array}{l}\text { The conversation } \\
\text { goes on for a } \\
\text { reasonable period } \\
\text { of time }\end{array}$ & $\square$ & $\square$ & $\square$ & $\square$ & \\
\hline 48. & $\begin{array}{l}\text { Avoids a } \\
\text { paternalistic } \\
\text { attitude }\end{array}$ & $\square$ & $\square$ & $\square$ & $\square$ & \\
\hline
\end{tabular}

\footnotetext{
${ }^{1}$ Paternalism according to MacMillanDictionary.com: a system in which someone in authority advises and helps people but also controls them by not letting them make their own decisions and choices
} 
Telenursing self-assessment tool

2014 Christina Johnson

\begin{tabular}{|l|l|l|l|l|l|l|}
\hline 49. & $\begin{array}{l}\text { Has a health } \\
\text { promoting attitude }\end{array}$ & $\square$ & $\square$ & $\square$ & $\square$ & \\
\hline 50. & $\begin{array}{l}\text { Gives continuous } \\
\text { information } \\
\text { throughout the call } \\
\text { about what is } \\
\text { happening (e.g. } \\
\text { documentation) }\end{array}$ & $\square$ & $\square$ & $\square$ & $\square$ & \\
\hline 51. & $\begin{array}{l}\text { Conveys a sense of } \\
\text { calm and security }\end{array}$ & $\square$ & $\square$ & $\square$ & $\square$ & $\square$ \\
\hline
\end{tabular}

